\title{
PRÁTICAS DE FORMAÇÃO ATENTAS À COLETIVIDADE
}

\author{
Laura Noemi Chaluh ${ }^{1}$ \\ Simone Gonçalves Reganhan ${ }^{2}$ \\ Keila Santos Pinto 3
}

\begin{abstract}
RESUMO: Neste artigo socializamos a pesquisa desenvolvida em um curso de extensão vinculado aos Projetos do Núcleo de Ensino promovidos no contexto da Pró-Reitoria de Graduação da Universidade Estadual Paulista "Júlio de Mesquita Filho" (UNESP). Do mesmo, participaram professoras coordenadoras, vice-diretoras, coordenadoras pedagógicas, vinculadas à Secretaria Municipal de Educação de Rio Claro, e alunas do curso de Licenciatura Plena em Pedagogia da referida universidade. O curso, com encontros mensais, é oferecido desde o ano de 2012. As práticas de formação instituídas e legitimadas, ao longo desses anos, buscaram sustentar uma concepção de formação que reconhece a dimensão da coletividade como instância fundante para pensar o fazer docente responsivo perante a escola. A partir do trabalho de análise dos registros produzidos por duas participantes foi perceptível a compreensão do quanto a promoção da coletividade fortalece o grupo e, consequentemente, interfere nas ações dos participantes nos seus respectivos contextos.
\end{abstract}

Palavras-chave: Formação de professores. Trabalho coletivo. Escola.

\section{TRAINING PRACTICES ATTENDING COLLECTIVITY}

ABSTRACT: In this paper we shared a work developed on an extension course linked to the Projects of the Teaching Nucleus promoted in the context of the Graduation ProRectory from the Paulista State University "Júlio de Mesquita Filho" (UNESP). That work has the participation of teaching coordinators, vice-principals, pedagogical coordinators, all them related to the Municipal Education Secretary of Rio Claro, and the participation of students from the course of Full-degree in Pedagogy of the mentioned university. The course, with monthly meetings, has been offered since 2012. The training practices established and legitimized throughout these years have sought to sustain a conception of training that recognizes the dimension of the community as a founding part to think the making of a responsive teacher before the school. From the analysis of records produced by two participants, it was possible to understand how much the promotion of the community strengthens the group and, consequently, interferes in the actions of the participants in their respective contexts.

Keywords: Teacher's formation. Collective work. School.

\footnotetext{
1 Profa. Dra. da Pós-Graduação em Educação, Instituto de Biociências da UNESP - Rio Claro. E-mail: Ichaluh@rc.unesp.br

${ }^{2}$ Mestre em Educação. Professora da Rede Municipal de Educação de Rio Claro - SP.

${ }^{3}$ Mestre em Educação. Professora da Rede Municipal de Educação de Rio Claro - SP.
} 


\section{PRÁCTICAS DE FORMACIÓN ATENTAS A LA COLECTIVIDAD}

RESUMEN: En este texto socializamos el trabajo realizado en un curso de extensión vinculado a los Proyectos del Núcleo de Enseñanza promovidos en el contexto de la ProRectoría de Graduación de la Universidad Estadual Paulista "Júlio de Mesquita Filho" (UNESP). De ese curso participaron profesoras coordinadoras, vicedirectoras, coordinadoras pedagógicas, vinculadas a la Secretaría Municipal de Educación de Rio Claro-SP-Brasil y alumnas del curso de Licenciatura Plena en Pedagogía de la citada universidad. El curso, con encuentros mensuales, es ofrecido desde el año 2012. Las prácticas de formación instituidas y legitimadas a lo largo de estos años buscaron sostener una concepción de formación que reconoce la dimensión de la colectividad como instancia fundante para pensar el hacer docente responsivo frente a la escuela. A partir del análisis de los registros producidos por dos participantes es perceptible la comprensión de cuánto la promoción de la colectividad fortalece el grupo y, consecuentemente interfiere en las acciones de los participantes en sus respectivos contextos.

Palabras clave: Formación de profesores. Trabajo colectivo. Escuela.

\section{Introdução}

O Programa do Núcleo de Ensino é de responsabilidade da Pró-Reitoria de Graduação (PROGRAD) da UNESP. Os Núcleos de Ensino ${ }^{4}$ têm como metas prioritárias a produção de conhecimentos na área educacional e a formação inicial e continuada do educador pautadas na articulação entre ensino, pesquisa e extensão. Segundo Rubo et al. (2015, p. 153), “desde os anos 1980, a formação de professores e a parceria com a escola pública são um foco prioritário" na UNESP.

As autoras fazem uma revisão histórica do Programa e explicitam que o Núcleo de Ensino (NE) surgiu em 1987, em um contexto de:

[...] grande mobilização da sociedade brasileira, marcada pelo movimento das Direitas Já, pela Assembleia Nacional Constituinte e, também, pelo processo de democratização da própria Unesp. Naquele momento, a instituição buscava construir uma nova relação universidade/sociedade, por intermédio de uma estratégia de ação junto à comunidade local ou regional que se concretizou mediante assessorias aos municípios e trabalhos sistemáticos junto à rede pública de ensino, com o objetivo de estabelecer uma relação horizontal e democrática com a comunidade, centrada fortemente na

4Informações disponíveis em: <http://www.unesp.br/portal\#!/prograd/nucleos-de-ensino17175/apresentacao/>. Acesso: 20 abr. 2016. 
O NE objetivava a elaboração de projetos colaborativos com o intuito de pesquisar a Educação Básica - Educação Infantil, Ensino Fundamental e Médio - em nível local e/ou regional. Para isso contou, e conta, com a participação de docentes da Unesp e de professores e especialistas da rede pública de ensino.

Rubo et al. (2015, p. 155) enfatizam que a grande contribuição do NE está no modelo de atuação:

[...] reunir no mesmo espaço e tempo graduandos, professores da rede pública de ensino e docentes da universidade, para a elaboração de projetos visando atender às demandas da escola pública. Para tanto, a Unesp, no início, proporcionou bolsas para graduandos e professores da rede pública, bem como recursos para material de consumo e transporte. Posteriormente, a bolsa para o professor da rede foi extinta, embora tivesse se mostrado como um incentivo fundamental à realização do trabalho junto à escola.

Esse modelo articulava atividades em duas vias. Por um lado, as atividades de ensino/pesquisa/extensão, das quais participavam alunos da graduação, permitia que os mesmos tivessem um contato maior com as problemáticas educacionais do contexto no qual estavam inseridos. Por outro lado, possibilitava que os professores da rede pública entrassem em contato com a universidade, "mediante discussão e implementações de ações decorrentes de pesquisas, orientadas por docentes dessa instituição, trazendo muitos deles inclusive de volta à vida acadêmica [...]" (RUBO et al., 2015, p. 154).

Segundo Rubo et al. (2015, p. 154), o NE se constitui numa importante inovação para a formação do professor, já que "a experiência acumulada até aqui pode dar subsídio para o planejamento de um novo modo de se organizar um curso de licenciatura". Destaca-se que o Programa do Núcleo de Ensino funciona como um

[...] elo integrador entre a sala de aula da universidade e a escola, entre a teoria e a prática, entre o aluno, o professor e rede pública de ensino, entre a pesquisa e a ação. Essa integração possibilitou a superação da dicotomia entre os diversos saberes e as práticas educacionais, de alguma forma abordados na formação inicial (RUBO et al., 2015, p. 154).

O objetivo do presente trabalho é socializar nossas experiências enquanto participantes de um Projeto do Núcleo de Ensino deixando em evidência que, além de o NE ser elo entre a escola e a universidade, essas propostas também se apresentam potentes ao promoverem a construção coletiva 
de conhecimentos. Assim, aqui problematizamos de que forma um espaço de formação vinculado aos Projetos do NE pode ser instituinte de práticas que favoreçam um fazer docente coletivo. Para a produção deste trabalho socializamos escritas produzidas por duas das autoras deste trabalho, Simone e Keila.

\section{O Programa do Núcleo de Ensino e os Projetos desenvolvidos}

Destacamos aqui os objetivos do Programa5: a) promover a parceria entre a Universidade e a escola pública; b) incentivar o ensino e a pesquisa de caráter disciplinar ou interdisciplinar nas unidades desde a Educação Infantil, no Ensino Fundamental e Médio do Sistema Público de Ensino; c) promover ações educativas e inclusivas junto aos movimentos sociais; d) apoiar a produção de material didático-pedagógico; e) contribuir com os processos de formação inicial dos graduandos da Unesp e de formação continuada dos professores da rede pública de ensino.

Todos os projetos precisam contemplar pelo menos uma das seguintes temáticas: os processos de ensino e de aprendizagem dos componentes curriculares; os processos de interação na escola; a política e a organização escolar; aspectos da formação e trabalho docente; o desenvolvimento de programas na escola e de parcerias entre a escola e a comunidade; políticas e processos de inclusão de alunos com necessidades educativas especiais; educação e cultura alimentar; elementos contemporâneos da cultura escolar brasileira. Os projetos vinculados ao Programa do Núcleo têm duração máxima de dois anos. A seguir, explicitamos a configuração dos Projetos do Núcleo de Ensino coordenados pela primeira autora deste trabalho e que foram desenvolvidos nos períodos 2012-2013, 2014-2015 e 2016-2017 (em andamento), na UNESP, campus de Rio Claro/SP.

No período 2012-2013, desenvolveu-se o projeto "Educar o olhar: filmes na formação de professores e alunos". O foco do trabalho estava na "educação do olhar" de alunos e professores a partir de filmes/documentários. Essa experiência estética possibilitava promover o conhecimento, o sentimento e a ação (DUSSEL, 2006), desencadeando uma reflexão ética e política, tanto de alunos

5 Objetivos correspondentes ao Edital 2016. Disponível em: <http://www.unesp.br/portal\#!/prograd/nucleos-deensino17175/edital-para-2016/>. Acesso: dez. de 2015. 
como de professores, ao ampliar a compreensão do mundo.

Algumas questões que guiaram as atividades propostas foram inspiradas nas questões colocadas por Dussel (2006), quando a autora pergunta-se: para que mostrar a dor? Buscamos a compaixão ou algum outro tipo de ação? Em um mundo saturado de imagens, todas impactantes, como fazer para evitar que a dor se banalize? Como podemos nos sentir tocados quando vemos alguém com fome, alguém ferido, alguém desamparado, se as imagens, rapidamente dão passo à seguinte notícia impactante e nada podemos fazer? E, finalmente, se questiona: “Como voltar a nós como vermos?" (DUSSEL, 2006, p. 290). As atividades tiveram como pano de fundo tentar responder essa pergunta em prol da sensibilização do olhar do educador.

No período 2014-2015, foi desenvolvido o projeto “Prática de leitura e literatura na formação de professores". O projeto de formação e intervenção tinha a intencionalidade de mostrar a potencialidade da leitura e da literatura no contexto educativo. As atividades desenvolvidas promoveram a prática da leitura com intuito de contribuir para a constituição de um sujeito leitor e esteve pautado na compreensão de que a prática da leitura é uma construção social e, por isto, a necessidade de criar condições para a promoção de propostas que efetivassem esta prática na escola e na universidade. Petit (2009) enfatiza que, ainda que na época atual as novas tecnologias possam trazer uma eventual diminuição da prática da leitura, "o gosto pela leitura e a sua prática são, em grande medida, socialmente construídos" (p. 22). Levando em consideração essa afirmação, foi feita a proposição do referido projeto.

O projeto proposto para 2016-2017 se intitula "Do exercício de leitura e escrita na formação do professor: horizontes para promover a autoria e o trabalho coletivo". O projeto de formação e intervenção tem a intencionalidade de contribuir na promoção do trabalho coletivo e da autoria de professores e alunos mediados pelas práticas de leitura e de escrita no contexto educativo (escola e universidade). A proposta pretende potencializar contextos para que os sujeitos vinculados ao projeto vivam e experienciem seu processo de empoderamento no coletivo do grupo. Trata-se de propostas que valorizam as práticas culturais como mediadoras da constituição de sujeitos que assumam a autoria do que produzem e que potencializem o fazer coletivo. Pensar em sujeitos autores implica dizer de uma formação da qual os sujeitos se sintam partícipes na/da construção do conhecimento, um conhecimento construído em um espaço de diálogo e escuta.

Destacamos que a literatura, os filmes, os curtas-metragens e outras práticas culturais ganharam espaço nos processos formativos atrelados aos três projetos acima contextualizados. Petit 
(2009, p. 289) destaca que

[...] a literatura, a cultura e a arte não são um suplemento para a alma, uma futilidade ou um monumento pomposo, mas algo de que nos apropriamos, que furtamos e que deveria estar à disposição de todos, desde a mais jovem idade e ao longo de todo o caminho, para que possam servir-se dela quando quiserem, a fim de discernir o que não viam antes, dar sentido às suas vidas, simbolizar as suas experiências.

Os três projetos vinculados ao $\mathrm{NE}$, acima referidos, foram organizados da mesma forma, tendo todos eles a mesma configuração. Por um lado, é oferecido o curso de extensão, "Escola: espaço de formação de professores", com encontros mensais e coordenado pela primeira autora do trabalho. 0 grupo que participa do curso está constituído por professoras coordenadoras6, vice-diretoras e coordenadoras pedagógicas7, todas elas vinculadas à Secretaria Municipal de Educação de Rio Claro, exercendo suas funções na Educação Infantil ou no Ensino Fundamental - Anos Iniciais. Um aspecto significativo é que desse curso também participam alunos do curso de Licenciatura Plena em Pedagogia (UNESP), alguns são bolsistas do Núcleo de Ensino e outros estão vinculados a outros projetos desenvolvidos pela coordenadora do curso, e há ainda aqueles que não possuem nenhuma vinculação a projetos.

Por outro lado, os alunos que são bolsistas do Núcleo de Ensino, além de participarem do encontro mensal no curso de extensão, têm a possibilidade de se inserirem em uma Escola de Ensino Fundamental - Anos Iniciais - para acompanhar semanalmente o trabalho pedagógico de uma professora naquela instituição. Isso possibilita que se iniciem no exercício da docência ao desenvolverem uma parceria com as professoras das salas, organizando o trabalho pedagógico de forma conjunta. A seguir, focaremos as possibilidades formativas desencadeadas no contexto do curso de extensão, promovido sistematicamente desde o ano de 2012.

${ }^{6}$ Professor eleito pela Equipe Docente e Gestora que, afastado de seu cargo, exerce a função de professor-coordenador na escola, desenvolvendo as seguintes ações: coordenar, acompanhar, avaliar e propor alternativas de solução do processo pedagógico no âmbito da unidade educacional.

${ }^{7}$ O Coordenador Pedagógico vinculado ao Centro de Aperfeiçoamento Pedagógico é responsável pelo desenvolvimento do Plano de Trabalho Pedagógico da Secretaria Municipal da Educação, promove cursos de formação continuada, oferece apoio técnico-pedagógico às equipes escolares. 


\section{Acerca do curso de extensão}

Os encontros no curso são mensais e a dinâmica está atrelada às necessidades das participantes, pois é com elas que vai se definindo o caminhar do grupo. As propostas encaminhadas dizem de uma concepção de formação continuada em que as participantes assumem que este espaço é uma construção coletiva e que diz da possibilidade de discutir juntas questões de interesse que surgem na interlocução. Nesse sentido, ainda que existam objetivos e eixos na proposta, os encaminhamentos vão sendo tecidos no grupo e com o grupo. Isso ainda diz da concepção de formação das participantes, já que, envolvidas no contexto do curso, estão também implicadas no delineamento das propostas e das questões a serem problematizadas.

Uma prática valorizada e instituída no curso é a prática da escrita. Após cada encontro, todas as participantes são convidadas a escrever, se expressarem, se mostrarem, se desvelarem. Trata-se de uma escrita que resgate pensamentos e sensações que foram desencadeados no encontro, estando juntas, discutindo juntas. Essas produções escritas são socializadas por meio do e-mail do grupo e permitem refletir, investigar e enxergar com outro olhar algumas situações que mobilizaram as discussões.

A partir do ano de 2016, no início de cada um dos encontros, três participantes ficam responsáveis por serem as "leitoras privilegiadas" dessas escritas, o que têm valorizado ainda mais os processos de escrita, a produção de sentidos enquanto leitores. Destacamos, aqui, a relevância desse momento, uma vez que essa prática tem levado as "leitoras privilegiadas" a criarem, inventarem, se arriscarem a envolver todo o grupo em uma atividade pensada a partir das escritas. Essas escritas potencializam atividades que nos levam a refletir, criando assim um movimento de envolvimento e implicação constante com o grupo, com as leituras, com as discussões.

As buscas pelas leituras ficam, geralmente, sob responsabilidade da coordenadora do curso. Porém essa busca está pautada nas inquietações e preocupações surgidas nos encontros, considerando as temáticas advindas da interlocução. Assim, no final de cada encontro, o coletivo define a temática que gostaria de abordar e discutir no próximo. O grupo, ao se posicionar, vai construindo uma teia de temáticas que implica na reflexão de práticas, experiências e posturas perante o outro e a educação.

Destacamos aqui que não se trata de um curso no qual as participantes "desabafam" seus dilemas, pelo contrário, é um espaço para que cada um assuma sua responsabilidade pelo lugar que 
ocupa no mundo. Sendo assim, na contramão do desabafo, a coordenadora do curso, atenta à fala de todas as participantes, elabora algumas questões para que elas se sintam desafiadas a refletirem sobre si mesmas e sobre sua atuação. Essa proposta foi instituída enquanto "desafio". Os "desafios" são provocações, são encaminhamentos ou ações que as participantes têm que desenvolver nos contextos escolares para resolverem e/ou enfrentarem questões que as inquietam. Essas ações, posteriormente, são socializadas nos encontros. Os desafios surgiram como uma brincadeira, como uma forma de pôr em movimento as participantes perante situações nas quais consideravam que nada era possível de ser feito. Os desafios colocaram as participantes no lugar de um sujeito de práxis, sujeito capaz de agir no mundo.

Destacamos que os "desafios" propostos foram importantes na construção de uma relação pautada no acolhimento, na intimidade, na aproximação, na construção de vínculos e na integração entre todos. Estes, sem dúvidas, foram muito mais do que momentos de superação. Foram momentos de crescimento pessoal, de quebra de barreiras, de rompimento dos limites, através do qual se estreitaram os laços e serviu como um sopro regenerador e motivador para deixar em evidência a importância de legitimar as pequenas ações que se desenvolvem no cotidiano escolar (CHALUH et al., 2015, p. 92).

A seguir, socializamos uma escrita produzida por Simone8 e que traz uma definição de como esses encontros se organizavam.

O que eu defino como "Metodologia Laura" [coordenadora do curso] segue
alguns passos, simples ao meu ver, e que descrevo da seguinte forma:
$1^{\circ}$ ) Imediatamente após dar as boas vindas, em cada um dos encontros
mensais, a professora pergunta: “O que nós vamos fazer hoje?", com seu
lindo sotaque espanhol. "Por onde começamos?" "Vamos primeiro ler o texto
ou ver o vídeo"? Como aprendi com esses textos... como me emocionei e me
encantei com os vídeos... entrei num novo mundo, conheci personagens reais
e imaginários pelas mãos de diversos autores, diretores, poetas, cineastas
que, por mim só, eu jamais teria os procurado.
2o) Então passamos para a leitura e discussão de um texto que foi socializado
por e-mail semanas antes dos encontros. Ou então, assistimos a algum vídeo
que a professora ou algum colega leva (cujo título ou tema foi decidido em
encontro anterior).
$3^{\circ}$ ) No transcorrer do encontro a professora faz anotações em seu

8 Nós, enquanto autoras e narradoras, nos responsabilizando pelas falas contidas nos nossos registros e autorizamos a deixar os nossos nomes tal qual foram enviados. 
caderninho. Nunca as vi. A impressão que tenho é que ela anota palavraschave sobre os posicionamentos que cada uma das participantes expõe. Anota pontos que lhe chamaram a atenção. Pontos que podem virar novas discussões.

$4^{\circ}$ ) Em nenhum momento, durante as discussões, ela faz intervenções que possam alterar ou influenciar os posicionamentos das participantes.

$5^{\circ}$ ) De repente, ela pede a palavra, procura por alguma das palavras-chaves de seu caderninho e lança um desafio para o grupo. Esses desafios vão desde as propostas de ações práticas dentro de nossas escolas até as propostas de produções escritas que nos deixam apavoradas, porque a primeira sensação é que ela está pedindo uma interpretação da letra do Hino Nacional Brasileiro ou a tradução de um texto escrito em mandarim. Pra mim, é nesse ponto que está o "segredo" da Metodologia Laura: o que venho crescendo com esses desafios não há como descrever. Foram a partir deles que iniciei minha deliciosa aventura de escrita das pipocas9; ou então que me levaram a certas mudanças em minha prática que eu jamais teria pensado em minha vida; esses desafios também me permitiram ler e ENTENDER (acreditem!!!) Manoel de Barros (sempre tive dificuldades com poesias e seus poetas); foi também por meio desses desafios que precisei me repensar como profissional, me reinventar, voltar atrás em alguns conceitos enrijecidos com o tempo.

$6^{\circ}$ ) Ao final dos encontros vêm novas perguntas: "E para a aula que vem? O que podemos ler?" "Quem se responsabilizará pelo texto ou pelo vídeo da próxima aula?" "Que tema discutiremos?" "O que mando para vocês lerem?" $7^{\circ}$ ) Por fim, o que completa a metodologia Laura, é o Registro Reflexivo combinado e instituído pelo grupo. Ela pergunta ao início de cada ano letivo: "Nós vamos continuar com os registros?" E, entre um encontro e outro, cada integrante posta, no e-mail do grupo, um Registro Reflexivo sobre o encontro. O melhor? Não há regras sobre como fazer esse registro. Cada um registra como quer. E se a autora do registro não se sentir à vontade para socializar com todo o grupo, o mesmo pode ser enviado apenas à professora, sem necessidade de dividir com as colegas. Entre um encontro e outro, as participantes vão lendo os registros das colegas, registrando opiniões, tecendo comentários, verificando onde as opiniões convergem ou divergem. Nesse momento não há intervenção nenhuma da professora Laura [...] (Simone, 2014).

Consideramos que a escrita da Simone explicita, contextualiza e dá vida a esses encontros mensais que têm provocado mudanças no fazer e pensar a docência tanto das educadoras em exercício como nas alunas da graduação, professoras em formação. Dentre as ações propostas, ela destaca a importância das práticas culturais que atravessam esses encontros: literatura, filmes, escritas. Práticas

${ }^{9}$ Pipocas Pedagógicas são crônicas escritas por professores, nas quais são relatados acontecimentos da vida escolar. 
que têm mobilizado a sensibilização do olhar, promovendo o estranhamento perante o vivido, interrogando, questionando, problematizando, sendo desafiadas, provocadas não apenas a repensar juntas à docência, e sim sendo provocadas a desenvolver outras formas de fazer a docência. Tudo isso em um contexto no qual as participantes vão aos poucos se revelando, se mostrando para o outro, criando vínculos e laços que possibilitam que todos ensinem e aprendam.

Segundo Riolfi (2002, p. 41), a importância de um sujeito incluir-se em um grupo tem como aspecto fundamental a possibilidade de entrar em um "movimento indissociável, me formar enquanto o outro se forma, cada um no seu tempo". A mesma autora considera que pensar em um grupo e no trabalho que nele pode ser desenvolvido exige a "vigência de um trabalho que suporta e sustenta a existência da diferença absoluta, da singularidade" (RIOLFI, 2002, p. 40).

A autora argumenta sobre a necessidade de uma pertença produtiva em determinado grupo: "acima de tudo, portanto, um grupo produtivo não é exatamente um lugar no qual se digam coisas importantes/relevantes, mas, sim, aquele no qual - de dentro do que pôde construir de próprio - o sujeito possa dizer" (RIOLFI, 2002, p. 43-44).

Trazemos as considerações de Chaluh (2008) que ao, argumentar sobre a constituição de grupos, explicita

Grupo, quando grupo, supõe a diferença individual, a singularidade. No grupo, quando grupo, as palavras ganham força, o sujeito assume a palavra, aparece o sujeito da enunciação. No grupo, quando grupo, as palavras entrelaçam-se e as palavras enunciadas pelos sujeitos geram acontecimentos. Acontecimentos: palavras tecidas, palavras que somam, palavras que formam, que produzem escrituras. Grupo, enlace de subjetividades que potencializa aos sujeitos da enunciação a promoção de sua produção, autoria e formação (CHALUH, 2008, p. 112, grifos das autoras).

Ainda, consideramos que a escrita de Simone explicita uma prática de formação que está sustentada em uma trilogia "linguagem-coletividade-empoderamento" (CHALUH, 2011a, 2012). Tratase de uma concepção de formação que tem como horizonte o empoderamento, que se dá na medida em que, os sujeitos, no caso, professoras em exercício e professoras em formação, se revelam para os outros, dizendo suas próprias palavras criticamente. Implica em um movimento de "contar a vida" e refletir sobre a vida vivida, levando em consideração as condições nas quais estamos inserindo, os que nos leva a tomar consciência da nossa própria história. 
Segundo Chaluh (2011b, p. 173), uma ação formativa que atente à formação de "sujeitos empoderados (pela palavra falada e escrita), passa necessariamente por oferecer contextos nos quais seja permitido que o outro fale". Isso implica considerar a linguagem como um dos aspectos centrais ao pensar em formação. Por isso, a importância de criar âmbitos nos quais a palavra possa circular. Assim, a linguagem (oral e escrita), é uma plataforma para que cada professor se aposse da palavra e, nesse movimento, se perceba como sujeito de enunciação. Segundo Miotello (2012, p. 143), “A palavra enunciada é uma palavra libertadora. Enunciar. Falar. Libertar a palavra. Liberdade que a palavra comporta por estar entre um homem que fala com outro homem que fala".

Também com Freire (1973) aparece a dimensão do diálogo:

\begin{abstract}
A existência, enquanto humana, não pode ser muda, silenciosa, nem nutrirse de falsas palavras, senão de palavras verdadeiras com as quais os homens transformam o mundo. Existir, humanamente, é "pronunciar" o mundo, é transformá-lo. O mundo pronunciado, por sua vez, retorna problematizado aos sujeitos pronunciantes, exigindo deles um novo pronunciamento (1973, p. 104$)^{10}$
\end{abstract}

A concepção embasada na referida trilogia é uma concepção de formação que está atenta ao coletivo. Isso porque concordamos com Freire $(1973$, p. 98) quando afirma que a "busca de ser mais, não pode se realizar no isolamento, no individualismo, mas sim na comunhão, na solidariedade dos que existem"11. Assim, no contexto do curso de extensão, a comunhão, a solidariedade, está presente, porque sabemos da potencialidade desse movimento para a transformação. E essa questão é fundamental, uma vez que sabemos que historicamente, "é comum que os professores se voltem para o isolamento em suas salas de aula, sendo poucas as ações construídas com os demais colegas/turmas e em outros espaços da escola ou fora dela" (ROCHA, 2012, p. 006335).

Segundo Davini (2001), as políticas e programas de formação deveriam priorizar os processos comunicativos, os trabalhos coletivos, a revalorização dos espaços comuns de aprendizagem e a construção do conhecimento compartilhado. A autora considera que os professores, frente às dificuldades que enfrentam no cotidiano escolar, assumem para si as mesmas, se responsabilizando

\footnotetext{
${ }^{10}$ Tradução das autoras.

${ }^{11}$ Tradução das autoras.
} 
por elas dentro das paredes da sala de aula. Nessa perspectiva, as dificuldades e problemas enfrentados são considerados próprios, individuais e pessoais. Por esse motivo, Davini (2001) argumenta contra esse mecanismo, uma vez que os professores assumem esses problemas como se tivessem um caráter "privado" quando, de fato, é "público".

busca por potencializar o caráter público do acontecimento escolar é que o curso, como considerado anteriormente, se sustenta naquela trilogia de formação que contempla a dimensão da coletividade. Para ampliar a compreensão do que entendemos por coletividade, a seguir, problematizamos essa questão. Apresentamos autores que, de diferentes perspectivas teóricas, concordam em um aspecto, o necessário estabelecimento de objetivos comuns em um grupo.

Fiorentini (2006) trata da temática a partir da diferenciação de dois conceitos que importam para as discussões deste trabalho: a cooperação e a colaboração. Segundo o autor,

Embora as denominações cooperação e colaboração tenham o mesmo prefixo co, que significa ação conjunta, elas diferenciam-se pelo fato de a primeira ser derivada do verbo latino operare (operar, executar, fazer funcionar de acordo com o sistema) e a segunda de laborare (trabalhar, produzir, desenvolver atividades tendo em vista determinado fim). Assim, na cooperação, uns ajudam os outros (co-operam), executando tarefas cujas finalidades geralmente não resultam de negociação conjunta do grupo [...]. Na colaboração, todos trabalham conjuntamente (co-laboram) e se apoiam mutuamente, visando garantir objetivos comuns negociados pelo coletivo do grupo. Na colaboração, as relações, portanto, tendem a ser não hierárquicas, havendo liderança compartilhada e co-responsabilidade pela condução das ações (FIORENTINI, 2006, p. 52).

Consideramos que várias das proposições de Fiorentini (2006) estão contempladas nas propostas do curso de extensão. O grupo, como um todo, tem clareza acerca da importância do apoio mútuo, da colaboração, da importância da promoção de relações de confiança em um espaço formativo de compartilhamento de experiências e que o objetiva repensar o fazer docente, promovendo possibilidades de mudanças no cotidiano em que cada uma de nós está inserida. $\mathrm{O}$ que unifica o grupo é não se contentar com as dificuldades, o que unifica o grupo é querer "ser mais", encontrando, nesse espaço de formação, possibilidades para superar os dilemas, provocar-se com os desafios e buscar estratégias que interfiram no cotidiano escolar de forma a mobilizá-lo em prol de um objetivo comum. 
Ainda, assumimos uma perspectiva na qual está explícita a ideia de que a constituição de um grupo não apaga as diferenças. Nessa linha, trazemos as considerações de Freire (2005) que argumenta a favor do reconhecimento dos diferentes que estão unidos no coletivo por um objetivo comum.

Quando digo unidade na diversidade é porque, mesmo reconhecendo que as diferenças entre pessoas, grupos, etnias, possam dificultar um trabalho em unidade, ela é possível. Mas é necessária, considerando-se a coincidência dos objetivos por que os diferentes lutam $A$ igualdade nos e dos objetivos pode viabilizar a unidade na diferença. A falta de unidade entre os diferentes conciliáveis ajuda a hegemonia do diferente antagônico. O importante é a luta contra o inimigo principal (FREIRE, 2005, p. 68).

Bakhtin (1999) considera o conceito de coletividade. Segundo o autor, quando os membros de uma coletividade estão unidos por "vínculos materiais objetivos", por exemplo, quando uma classe social já amadureceu a noção de "classe para si", os membros dessas coletividades têm a possibilidade de desenvolver, a partir de sua atividade mental (consciência), "o protesto", não havendo lugar para uma "mentalidade resignada e submissa". Assim, os membros de cada coletividade, frente a uma problemática real, se unem com o objetivo de procurar uma solução às dificuldades achadas, enunciando sua contra palavra (BAKHTIN, 1999).

Ao pensarmos nas dimensões do trabalho coletivo aqui tratadas, enfatizamos que esse trabalho não implica em que cada uma das participantes abandone suas marcas, sua singularidade. Reforçamos aqui que é justamente a diferença, a marca do outro, o reconhecimento do outro no trabalho coletivo que ampliam e contribuem na busca pelo objetivo comum.

\section{Formação e coletividade: da percepção de Simone}

A fim de socializar de que forma o curso de extensão contribuiu na percepção da ideia de coletividade na formação continuada de professores e no desenvolvimento da ideia de que esse conceito, no espaço escolar, pode colaborar com a formação dos profissionais envolvidos no processo 
educacional, foram reunidos alguns trechos dos Registros Reflexivos produzidos por Simone ${ }^{12}$. A participante afirma em seu Registro Reflexivo, referente ao encontro ocorrido em junho de 2013

Pensei na nossa discussão e refleti sobre o quanto está faltando em nossas escolas a sensibilização, o sentimento de cuidar e se importar com o outro. Pensarei com carinho nas perguntas que a professora Laura nos deixou, pois preciso assumir meu papel, entender a minha responsabilidade nessa cegueira coletiva em que nos encontramos quando o assunto é o outro, o próximo [...]. Senti também que aquela professora [referência feita à professora do filme "Escritores da Liberdade"] vai além do que "é da sua obrigação". Ela é capaz de descentrar-se: sair de si e ser capaz de enxergar o outro por meio de sua fala, de seu riso, de sua lágrima, de sua linguagem, de seu comportamento. Ela é capaz de entender seu aluno e suas necessidades. Ela construiu uma prática - e digo CONSTRUIU porque ela não chegou sabendo o que fazer. Ela procurou formas de atingir seus alunos e dar-lhes tudo o que necessitavam. Ela mudou o que havia planejado. Fez autocrítica e entendeu que algo ainda faltava. Acho que precisamos ver isso e nos lembrarmos, todo santo dia, de todas as coisas e pessoas pelas quais somos responsáveis e o quanto nossa atitude é capaz de construir ou destruir alguém (Simone, junho de 2013).

Nesse registro observa-se um "pontapé" inicial para a percepção do outro. Os encontros proporcionam reflexões e sensibilização capazes de fazer com que seus participantes se sintam parte de um grupo que possui uma intenção "coletiva". Essa percepção acontece em dois sentidos: no primeiro sentido, por ser uma formação que acontece em um grupo, com uma grande diversidade de pessoas, com os mesmos anseios e intenções; e, num segundo sentido, porque cada participante está sendo formado para trabalhar na educação "por meio" e "para" a coletividade. Em outro Registro Reflexivo do ano de 2013, Simone afirmou:

Tenho visto nos filmes e documentários usados no nosso curso de formação uma possibilidade imensa de fazer profundas reflexões sobre "ser professor". Todos os sentimentos que afloram têm sido muito importantes para uma mudança de postura e de atitudes em minha prática pedagógica. As reflexões também têm sido muito importantes para minha vida pessoal como mãe, esposa, irmã, filha, amiga... Como podem "seres humanos" serem tão especiais? O que possuem de diferente? Por que eu não posso ser assim também? Como ser uma pessoa tão especial para aqueles com que eu

\footnotetext{
12 Segunda autora deste trabalho, vice-diretora de uma escola de Ensino Fundamental - Anos Iniciais e professora de uma
} faculdade particular durante os anos de 2013 a 2016, considerados como fontes de dados e de análise para discussão. 
convivo? Será que um dia serei capaz de provocar um frenesi em alunos com as quais trabalhei? Juro... não sei!!! Já estou começando a achar que vai ser somente por obra divina... rs, rs, rs... brincadeira! Vou tentar... tentarei me livrar das amarras emocionais, sociais, humanas para descentralizar; parar de achar que sou dona dos acontecimentos, dona da verdade... É muito bom ver que existem pessoas que já fazem isso, e de forma brilhante. O lado positivo de vermos a proposta do professor que protagoniza o documentário "Pensando nos demais" é o de ter a certeza de que é possível uma prática educacional tão humana e poder conferir os resultados maravilhosos que ela produz. Como está sendo importante pra mim, fazer parte desse grupo de formação. O trabalho coletivo de formação é muito rico, além de ser enormemente prazeroso.

Observa-se por meio desse registro que a participante percebe a importância da coletividade em seu processo de formação continuada. Ainda em 2013, a participante faz as seguintes observações após o oitavo encontro da formação.

O último encontro deixou em mim uma marca muito forte sobre a importância do aprender sempre. Fiquei muito feliz ao perceber que, enquanto seres humanos, DETENTETORES da capacidade de ERRAR, também DOMINAMOS o dom da REDENÇÃO. Essa capacidade nos permite repensar a cada segundo nossas ações, os pensamentos que nos envolvem, as palavras proferidas... Que booooommmmm! A capacidade de errar - além de nos permitir fazer "burradas" - também nos permite que voltemos atrás, que nos repensemos, que nos recriemos. Ouvi com atenção as colegas falando no último encontro sobre: as dificuldades com as características pessoais de cada um; do "olhar" com cuidado para o outro; mudança de postura; olhar para a imagem que eu tenho na escola; encontrar momentos para acolher e "enxergar" esses momentos; pensei sobre como está sendo bom ter um espaço para refletir sobre minhas atitudes como educadora e ganhar o direito de me redimir, de refazer, de repensar! Como diz Paulo Freire "[...] por isso aprendemos sempre." Agradeço pela oportunidade de aprender SEMPRE! (Simone, novembro de 2013).

Interessante observar que a participante se coloca na condição de aprendiz a partir da "escuta dos colegas". Ela afirma aprender com as narrativas feitas pelos participantes do grupo durante os encontros da formação. Isso permite compreender que a formação continuada do profissional da educação, por meio da coletividade, pode trazer resultados significativos para o processo de reflexão da atuação docente.

Em um dos registros de 2014, Simone apresenta para o grupo, sua escrita, seu Registro Reflexivo. Nele socializa uma prática de uma tribo africana, conhecida como "Sawabona". Sawabona é um costume de levar a pessoa que fez algo errado para o centro da aldeia para que, durante dois dias, a tribo a rodeie e diga todas as coisas boas que ela já fez. Essa prática parte da premissa de que cada 
ser humano vem ao mundo como um ser bom. Cada um de nós desejando segurança, amor, paz, felicidade. Mas, às vezes, na busca dessas coisas, as pessoas cometem erros. A comunidade enxerga aqueles erros como um grito de socorro. Eles se unem então para erguê-la, para reconectá-la com sua verdadeira natureza, para lembrá-la quem ela realmente é, até que ela se lembre totalmente da verdade da qual ela tinha se desconectado temporariamente: "Eu sou bom". Sawabona é um cumprimento usado na África do Sul que quer dizer: "Eu te respeito, eu te valorizo. Você é importante pra mim". A participante, diante do relato dessa prática africana, afirma então, em seu Registro Reflexivo: "Espero poder sempre contar com a paciência de vocês para que possam me colocar no centro da roda para dizerem pra mim: SAWABONA".

Percebe-se o quanto Simone confia no grupo e acredita que a sua formação possa receber a participação e sofrer grandes intervenções a partir das "vozes" das demais participantes. Ela se coloca na condição de aprendiz perante o coletivo, fazendo uma analogia ao costume da tribo.

Esse discurso da participante se repete ao longo de vários registros, durante os três anos e meio de participação na formação. Muitos deles reforçam como a construção coletiva do seu processo de formação é fundamental para que entenda seu papel na coletividade também na escola onde atua. Segue um trecho de um registro de 2015.

Se não fosse o grupo de professoras e alunas de pedagogia com a qual me encontro mensalmente, não sei o que teria sido de mim. Falei, chorei, gargalhei, ouvi, dividi, somei, multipliquei. Dali, as únicas coisas subtraídas foram algumas tristezas, que depois de compartilhadas, tiveram seus pesos reduzidos de dentro de mim. Ufa! Que bom! (Simone, abril de 2015).

Em outro registro, feito no ano de 2015, a participante faz uma analogia a outro costume africano que defende a ideia de que "um" não pode ser feliz se todos os outros estiverem tristes. Isso se chama, na tribo Xhosa, Ubuntu: "Eu sou porque nós somos”. E completa a ideia dessa ligação com o próximo com o seguinte registro:

Participando de um grupo de formação de professores, na Unesp (Rio Claro) tive a deliciosa oportunidade de aproximar-me de pessoas maravilhosas, profissionais que eu já conhecia de "outros carnavais", mas com quem não tinha tido a oportunidade de cruzar olhares a fundo. Nos encontros mensais, organizados pela professora Laura Chaluh, em que participam alunos de graduação em Pedagogia, da pós-graduação e professores da rede pública de ensino (de diferentes escolas do município), temos a oportunidade de nos aproximarmos até de forma íntima, dos anseios, das angústias, dos desejos, das dores e das necessidades de cada um dos participantes. Nossas conversas e reflexões giram em torno de variados assuntos, todos eles praticamente 
voltados à gestão da escola e de pessoas (Simone, novembro de 2015).

Por fim, cursando o quarto ano consecutivo da formação, a participante continua no processo de compreensão da coletividade.

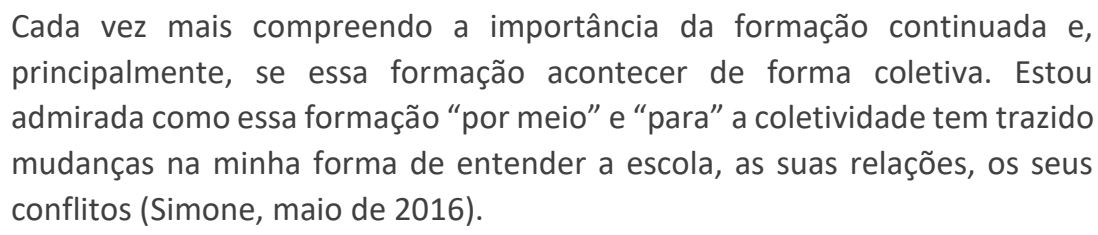
admirada como essa formação "por meio" e "para" a coletividade tem trazido mudanças na minha forma de entender a escola, as suas relações, os seus conflitos (Simone, maio de 2016).

Os dados apresentados nos relatos da participante em relação ao seu processo de formação continuada apontam para a ideia do alargamento dos conceitos de prática, não restringindo ao contexto da sala de aula e da gestão da escola, metodologias e estratégias utilizadas pelos professores nas práticas educativas e pelos gestores na organização e funcionamento da escola. Por meio das vozes dos colegas, a participante reconhece e toma consciência da construção do conceito de coletividade na formação do professor e do gestor escolar.

Assim como Sacristán (1999), a participante concluiu que a prática educacional é perpassada por práticas concorrentes, as quais não são estritamente pedagógicas e, mesmo fora do sistema escolar, exercem grande influência sobre as próprias atividades técnica dos professores e gestores. Também concluiu que, num contexto colaborativo, coletivo e dialógico (como ocorrido durante os três anos e meio em que participa do Grupo de Formação em questão), foi possível alcançar uma visão ampla sobre a relevância do fazer coletivo nas diversas áreas de atuação da escola.

Para Nóvoa $(1999$, p. 18) é impossível imaginar alguma mudança que não passe pela formação de professores. Segundo o autor, não se trata de "mais um programa de formação" a se juntar a tantos outros que todos os dias são lançados. Faz-se necessário uma outra concepção, que situe o desenvolvimento pessoal e profissional dos professores, ao longo dos diferentes ciclos de sua vida, que valorize a experiência como aluno, como aluno-mestre, como estagiário, como professor principiante, como professor titular e, até, como professor reformado.

Dialogamos mais uma vez com Riolfi (2002), já que a autora explicita que na formação de grupos não temos que olhar apenas para a decisão das pessoas de realizarem um trabalho conjunto, mas, especialmente, olhar para a instauração de um determinado tipo de laço que permita que um trabalho tenha a potência de ser formativo, ou seja, que esse trabalho tenha consequências. A autora argumenta sobre a necessidade de uma pertença produtiva em determinado grupo: "acima de tudo, 
portanto, um grupo produtivo não é exatamente um lugar no qual se digam coisas importantes/relevantes, mas, sim, aquele no qual - de dentro do que pôde construir de próprio - o sujeito possa dizer" (RIOLFI, 2002, p. 43-44).

Assim, que o "sujeito possa dizer" implica voltar na concepção de formação apontada anteriormente, a trilogia, na qual a linguagem e a coletividade ganham um patamar especial na medida em que com e a partir delas, os sujeitos se empoderam, quando sabem que podem dizer sua palavra criticamente. Simone, com seus Registros Reflexivos, deixou com clareza que foi se apropriando da linguagem, de dizer para um outro, de mostrar para tantos outros, o quanto estando naquele grupo Ihe possibilitou um processo formativo diferenciado, porque pensado coletivamente. Esse grupo de formação, da qual tratamos neste artigo, possui essa diversidade de experiências, que integra as dimensões do cotidiano da escola, fazendo com que este seja parte essencial da definição de cada um como professor/gestor.

\section{Formação e coletividade: desafiando Keila}

Como já referido, durante o curso as participantes foram provocadas a produzir sentidos, a partir das próprias práticas enquanto coordenadoras pedagógicas, vice-diretoras, professoras coordenadoras e alunas da graduação. Essa produção mobilizou a buscar formas de compreender o trabalho e os lugares que cada participante ocupava na escola e na universidade.

Em um dos encontros do ano de 2013, foi proposto para Keila, professora coordenadora e terceira autora deste trabalho, um desafio que desencadeou a ampliação da sua interlocução na escola e, consequentemente, promoveu mudanças nos seus modos de pensar e fazer a coordenação pedagógica nos espaços de formação em uma escola municipal de Educação Infantil.

Esse fato aconteceu quando no grupo se discutia acerca dos processos de formação na escola, indiciando o quanto a dimensão humana e a valorização das experiências estavam ausentes nesse contexto. Nesse dia, Keila socializou com o grupo o quanto sentia necessidade que as educadoras 
(professoras e monitoras) ${ }^{13}$ de sua escola se expressassem mais, não somente por meio de conversas, mas de outras formas. Keila queria que as educadoras revelassem seus interesses e necessidades para que assim ela pudesse ter mais elementos que a auxiliassem no seu trabalho enquanto professora coordenadora na escola. Nessa perspectiva, ela apontou seu desejo de intensificar a interlocução, por meio da prática de escrita, considerando a produção de registros na escola, para além de escritas pontuais e técnicas que já eram produzidas, tais como planos de trabalho e diários de bordo.

A questão era que Keila, enquanto professora coordenadora e responsável pela organização dos espaços de formação na escola, queria que os outros escrevessem, para que assim pudessem se expressar e revelar seus sentimentos. Porém, a coordenadora do curso perguntou para ela o quanto ela escrevia para as educadoras da escola. $O$ desafio estava posto. Foi nesse momento que aflorou em Keila o desejo de escrever para as educadoras. A partir daí Keila começou a pensar de que forma iniciar uma interlocução escrita para as educadoras de sua escola que pudesse contribuir com o trabalho de ambas. Ela se envolveu nessa proposição da escrita e, no primeiro momento, escreveu uma carta às educadoras da escola, a partir da intenção de criar um movimento de escrita, movimento este que não fosse pautado como imposição, mas como uma ação livre de expressão e modos de falar sobre si.

Essa primeira carta foi escrita à mão pela professora coordenadora, que fez várias cópias e logo após entregou a cada uma das educadoras da escola. Ao entregar a carta, Keila falou para as educadoras que se sentissem à vontade de respondê-la ou não.

A carta revelava o olhar da professora coordenadora acerca do primeiro semestre letivo do ano de 2013, ao apontar a importância da função de cada uma na escola; o período inicial do ano e a relação entre educadoras, crianças e familiares; o planejamento e realização das atividades; o desenvolvimento das crianças e as reivindicações do grupo. Para a surpresa de Keila, no dia seguinte ela começou a receber cartas em resposta à que tinha entregue. Em dois dias, mais da metade das

\footnotetext{
${ }^{13} \mathrm{Na}$ escola em que Keila atua como professora coordenadora trabalham monitoras e professoras, sendo que nas salas dos berçários trabalham somente as monitoras e nas salas de maternal I as professoras trabalham no período da manhã junto com as monitoras que trabalham em período integral. Dessa forma, na escola, pautado no trabalho educativo que é realizado com as crianças, consideramos que todas são educadoras. Em 2014, o grupo era constituído por vinte monitoras e cinco professoras.
} 
educadoras já tinham Ihe respondido as cartas e, passada uma semana, das vinte e três educadoras, somente quatro não tinham escrito a ela.

A troca de cartas possibilitou que a professora coordenadora refletisse sobre o trabalho que realizava na escola, o que lhe permitiu delinear caminhos para melhorar a organização do seu trabalho. Keila percebeu o quanto as educadoras se sentiram valorizadas ao receberem uma carta que apresentava aspectos referentes ao cotidiano do qual faziam parte.

Ao ler as cartas-resposta, os sentimentos de Keila afloraram, pois eram escritas comoventes, que expressavam sentimentos reveladores de si mesmo, possibilitando relações de aproximação e intimidade entre professora coordenadora e educadoras. A partir desse movimento de escrita, criouse um amplo espaço de interlocução que permitiu a organização de um trabalho de formação mais humano e sensível. Assim, o desafio posto no curso de extensão, que foi traduzido por Keila com a proposta de escrita de cartas, a auxiliou na escola, ao potencializar suas ações enquanto professora coordenadora e ao oportunizar às educadoras e a si mesma a autoria das ações desenvolvidas e a compreensão das múltiplas situações vivenciadas na escola.

Posteriormente, Keila compartilhou essa experiência no curso. Leu a carta escrita por ela e revelou suas percepções em relação a esse desafio. Para ela, esse momento de compartilhamento do desafio proposto e suas implicações foi especial e as colegas do curso de extensão acolheram seus sentimentos. Segue o registro reflexivo produzido por Keila após socializar essa sua experiência com as demais participantes do curso:

Esse encontro foi muito especial. Desde que começamos a nos reunir [no curso], tivemos muitos ganhos, construímos novos saberes, adquirimos força, conquistamos novas relações, recebemos compreensão e "dicas", compartilhamos sentimentos, recuperamos a vontade de fazer a diferença no nosso ambiente de trabalho, principalmente ao considerar a dimensão humana presente cotidianamente na nossa prática.

Conseguimos com esse encontro reputar a afetividade e a emoção, prerrogativas essenciais ao trabalho do educador. Estamos acostumados, como já discutimos em outros encontros, a agir muitas vezes de forma técnica, mostrando o que é mensurável, o produto final, e na dinâmica do dia a dia, esquecemo-nos de olhar para o outro e para nós mesmos.

A busca por uma relação de parceria e confiança, através dos afetos positivos, a liberdade de se expressar o que sente, de fazer escolhas e exercer a autonomia é imprescindível no ambiente escolar.

O sentimento de estar bem (à vontade) no encontro [curso de extensão] permitiu-me as possibilidades de trocas e os desabafos, talvez em outro momento eu pudesse sentir-me desconfortável, ao me expor demais, mas devido a atenção e compreensão das companheiras, senti-me confiante e 
confiei em cada uma [...].

Esse foi o encontro do olhar para si, o encontro que permitiu a reflexão da nossa prática e o entusiasmo para a ação.

Terapia em grupo, exercício de autoconhecimento, trocas de angústias e alegrias, desabafos, compartilhamento de experiências, curso de formação, estamos vivenciando a multiplicidade de acontecimentos, que de certa forma nos ampara (Keila, agosto de 2013).

A partir dos desafios propostos às participantes no curso foram possíveis práticas que enunciassem distintos modos de organização dos espaços de formação na escola, sendo estes espaços momentos fecundos para mobilizar o trabalho coletivo.

Escrever as cartas para as educadoras disparou ações em prol de um espaço de diálogos, que culminou em outros modos de se expressar na escola e assim a professora coordenadora ampliou os momentos de registro, por meio do seu diário pessoal, um caderno no qual ela diariamente registrava suas impressões e sentimentos sobre os acontecimentos cotidianos; o diário de Horas de Trabalho Pedagógico Coletivo (HTPC), uma proposição de registro coletivo feita por ela no início do ano de 2014 às educadoras; e os registros reflexivos, escritas solicitadas pela professora coordenadora a partir de determinado tema de estudo, leituras e acontecimentos cotidianos.

Segundo Keila, para sensibilização do olhar e a realização do trabalho coletivo no contexto da escola em que ela está inserida, foi relevante colocar-se diante do exercício de escutar, uma escuta que não apresentou somente situações prazerosas, mas revelou os conflitos do coletivo, a partir de uma proposta de formação que se apropriou da leitura do real, ao incentivar a investigação do cotidiano, e propor desafios que nos provocassem a produzir espaços coletivos. Coletividade como aquela capaz de ouvir todas as vozes com acolhimento e cuidado. O movimento disparado pelo desafio de escrever às educadoras desdobrou-se em uma experiência formativa na qual a coletividade, a parceria, a corresponsabilidade e a valorização do trabalho redimensionaram o cotidiano da escola. $\mathrm{E}$ foi a partir desse desafio que Keila inseriu-se no processo de pesquisar a própria prática, o que culminou na produção de uma dissertação de mestrado (PINTO, 2016).

\section{Considerações finais}

Fica claro para nós que os encontros no curso de extensão nos sensibilizaram de tal forma, que chegávamos transbordando na escola, transbordavam nossos olhares, sentimentos, palavras e a busca por provocar no outro o que estava sendo provocado em nós no referido curso. Esse era o nosso maior 
desafio, e para isso nos movíamos, pensando nas nossas estratégias de trabalho, enquanto formadoras.

Nessa perspectiva, foi possível pensar um fazer mais centrado no diálogo e na construção de um espaço de coletividade na escola, já que durante o curso percebeu-se que estava se incutindo um "círculo de contribuições", por meio de mobilizações de apoio e de ajuda mútua, tanto entre nós do curso, como entre a maioria das participantes em suas escolas, o que permitiu algumas mudanças no ambiente escolar, pois cada uma de nós autorizou-se a olhar para si e para o outro (PINTO, 2016).

As propostas de atividades no curso legitimaram a dimensão da sensibilização do olhar e se constituíram num outro modo de pensar a formação na escola, modos de resistir ao conformismo e ao tempo-espaço atual, o qual apresenta a escola distanciada das dimensões afetivas e estéticas, ao priorizar a dimensão racional. Assim, constantemente durante o curso fomos interrogadas acerca dos nossos olhares na, da e para a escola, ao refletir coletivamente sobre o nosso trabalho e sobre nós mesmos: o que sou? e o que estou sendo aos outros?

Algumas das insatisfações compartilhadas no grupo desvelavam a excessiva preocupação em solucionar problemáticas imediatas, por isto a proposta de sensibilizar o olhar, para que assim não nos esquecêssemos de considerar dimensões mais humanas, para superar o automatismo e o controle presentes na escola. Foi possível perceber no curso que a sensibilização do olhar mobiliza o trabalho coletivo, na medida em que intensifica as interações estabelecidas no cotidiano entre aqueles que habitam o mesmo espaço e se posicionam criticamente e esteticamente diante do mundo, ao buscarem objetivos comuns.

Nessa perspectiva, há de se interrogar a realidade e enfrentar os desafios promovendo ações que permitam a emoção, criação, invenção, o cuidado e valorização do outro. Esses pontos foram determinantes para que, enquanto formadoras, pudéssemos pensar sobre a nossa própria prática e o quanto conseguíamos alcançar o outro a partir disto.

Compreendemos que são necessários outros olhares para a formação de professores e para a escola, pautados no trabalho coletivo ao superar práticas individualistas ou culpabilizadoras dos professores pela má qualidade do ensino, ao desconsiderar e desvalorizar as ações realizadas no cotidiano escolar. Nessa perspectiva, a formação como sensibilização do olhar e promoção do trabalho coletivo foi vista como espaço privilegiado de atribuição de sentidos e de encontro, encontro consigo mesmo e com outro, ao valorizar as histórias de vida e os saberes da experiência, apresentando para o grupo do curso de extensão outro paradigma de atuação na escola e na universidade. 


\section{Referências}

BAKHTIN, M. Marxismo e filosofia da linguagem. São Paulo: Hucitec, 1999.

CHALUH, L. N. Formação e alteridade: pesquisa na e com a escola. 2008. 290f. Tese (Doutorado em Educação) - Faculdade de Educação, Universidade Estadual de Campinas, Campinas, 2008.

. Formação inicial de professores: grupo, diálogo e trabalho coletivo. In: I CONGRESSO NACIONAL DE FORMAÇÃO DE PROFESSORES, XI CONGRESSO ESTADUAL PAULISTA SOBRE FORMAÇÃO DE EDUCADORES, POR UMA POLÍTICA NACIONAL DE FORMAÇÃO DE PROFESSORES, 2011a, Águas de Lindóia, Anais... Águas de Lindóia: UNESP, 2011a, p. 972-983.

. Futuros professores: um processo coletivo de formação. In: Grupo de Estudos dos Gêneros do Discurso [GEGe], Questões de cultura e contemporaneidade: o olhar oblíquo de Bakhtin. São Carlos: Pedro\& João Editores, 2011b. p.161-174.

. Percursos na formação inicial de professores. In: CHALUH, L. N. (Org.), Escola-Universidade: olhares e encontros na formação de professores. São Carlos: Pedro \& João Editores, 2012. p. 11-25.

CHALUH, L. N. et. al. Educar o olhar: filmes na formação de professores. In: Núcleos de Ensino da Unesp [recurso eletrônico]: artigos 2013. COLVARA, L. D.; OLIVEIRA, J. B. B. (Orgs.), Dados eletrônicos (1 arquivo). São Paulo: Cultura Acadêmica: Universidade Estadual Paulista, Pró-Reitoria de Graduação, 2015. p. 89-110.

DAVINI, M. C. La formación docente en cuestión: política y pedagogía. Buenos Aires: Paidós, 2001.

DUSSEL, I. Educar la mirada. Reflexiones sobre una experiencia de producción audiovisual y de formación docentes. In: DUSSEL, I.; GUTIERREZ, D. (compiladoras), Educar la mirada: políticas y pedagogías de la imagen. Buenos Aires: Manantial: Flacso, OSDE, 2006. p. 227-293.

FIORENTINI, D. Pesquisar práticas colaborativas ou pesquisar colaborativamente? In: BORBA, M. C.; ARAÚJO, J. L. Pesquisa Qualitativa em Educação Matemática. 2. ed. Belo Horizonte, MG: Autêntica, 2006. p. 49-78.

FREIRE, P. Pedagogía del oprimido. Tradução de Jorge Mellado. 7. ed. Buenos Aires: Siglo Veintinuno/Argentina Editores, 1973.

. À sombra desta mangueira. São Paulo: Olho D’Agua, 2005.

MIOTELLO, V. Empoderamento e linguagem. In: CHALUH, L. N. (Org.), Escola-Universidade: olhares e encontros na formação de professores. São Carlos: Pedro \& João Editores, 2012. p. 139-143.

NÓVOA, A. Os professores na virada do milênio: do excesso dos discursos à pobreza das práticas. Educação e Pesquisa. São Paulo, v. 25, n. 1, p. 11-20, jan-jun, 1999.

PETIT, M. A arte de ler ou como resistir à adversidade. Tradução de Arthur Bueno e Camila Boldrini. São Paulo: Editora 34, 2009.

PINTO, K. S. Desdobramentos das escritas de educadoras nos espaços de formação na escola. 2016, 190f. Dissertação (Mestrado em Educação) - Instituto de Biociências, Universidade Estadual Paulista, Rio Claro, 2016.

RIOLFI, C. O amor à diferença no trabalho enlaçado no interior de grupos. Trabalhos em Linguística Aplicada, Campinas, v. 39, p. 37-45, jan/jun. 2002. 
ROCHA, M. S. P. Desafios na construção do trabalho coletivo nas escolas para a (trans) formação docente. In: LEITE, Y. U. F. et al., (Orgs.), Políticas de formação inicial e continuada de professores. Araraquara, SP: Junqueira\&Marin, 2012. p. 006334-006345.

RUBO, E. A. A. et al. Do Núcleo de Ensino ao Pibid: contribuições da Unesp à formação de professores. In: Gatti, B. A. et al. (Orgs.), Por uma revolução no campo da formação de professores. São Paulo: Editora Unesp, 2015.

SACRISTÁN, J. G. Consciência e a ação sobre a prática como libertação profissional dos professores. In: NÓVOA, A. (Org.), Profissão Professor. Portugal: Porto Editora, 1999. p. 63-92.

Recebido em: 13/08/2017

Aceito em: 19/12/2017 